\title{
A strategy for pulmonary resection after contralateral diaphragm plication: a surgical case report
}

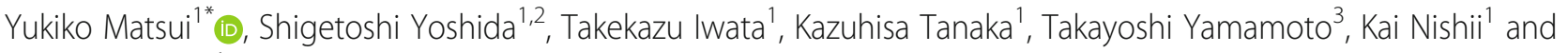 \\ Toshihiko lizasa ${ }^{1}$
}

\begin{abstract}
Background: Pulmonary carcinoma patients with low pulmonary function cannot be treated surgically because of the high risk of complications. Diaphragmatic eventration is a disease characterized by diaphragmatic paralysis and dyspnea. Here, we report a surgical case of multiple pulmonary carcinomas with contralateral diaphragmatic eventration.

Case presentation: The patient was a 75-year-old woman with multiple metachronous right lung carcinomas complicated by left diaphragmatic eventration. When she was 70 years old, a right upper lobectomy and right $S^{6} b$ wedge resection were performed for double lung carcinomas. Five years later, two new lung tumors in her right lower lobe and left diaphragmatic eventration were identified, but resection was thought to be impossible because of her low pulmonary function. We performed video-assisted thoracoscopic surgery (VATS) plication with carbon dioxide $\left(\mathrm{CO}_{2}\right)$ insufflation for the left diaphragmatic eventration, and her pulmonary function improved.

Subsequently, we performed a right $S^{6}$ wedge resection and right $S^{9}$ segmentectomy for the double lung tumors with no complications. The tumors were diagnosed as double primary carcinomas.

Conclusions: Our case presented with low pulmonary function and right multiple lung carcinomas with left diaphragmatic eventration. VATS plication for the left diaphragmatic eventration achieved improvement in her pulmonary function, and right pulmonary resection for the lung carcinomas was performed. VATS plication can expand the choice of treatments in such cases.
\end{abstract}

Keywords: VATS diaphragm plication, $\mathrm{CO}_{2}$ insufflation, Multiple lung carcinomas, Pulmonary function

\section{Background}

Pulmonary function is an important factor to consider for patients with lung diseases when evaluating surgical treatment options. Patients with low pulmonary function cannot be treated surgically because of the high risk of complications.

Diaphragmatic eventration is a disease characterized by diaphragmatic paralysis and dyspnea. Patients with severe symptoms should be considered for surgical treatment.

Here, we report a patient with right multiple lung carcinomas, low pulmonary function, and left diaphragmatic eventration. We performed video-assisted thoracoscopic surgery (VATS) plication using $\mathrm{CO}_{2}$ insufflation for the

\footnotetext{
* Correspondence: ymatsui@chiba-cc.jp

'Department of Thoracic Surgery, Chiba Cancer Center, 666-2 Nitona-cho,

Chuo-ku, Chiba 260-8717, Japan

Full list of author information is available at the end of the article
}

left diaphragmatic eventration. The procedure resulted in the improvement of her respiratory function; subsequently, we performed right pulmonary resection for the lung carcinomas.

\section{Case presentation}

A 75-year-old woman was admitted in our hospital after a right upper lobectomy and right $S^{6} b$ wedge resection for synchronous double lung cancer 5 years previously. The preoperative computed tomography (CT) images showed a right $S^{2}$ tumor and a right $S^{6} b$ peripheral tumor (Fig. 1a, b). Metachronous double lung tumors in the right lower lobe $\left(S^{6}\right.$ a and $\left.S^{9}\right)$ and left diaphragmatic eventration were detected with $\mathrm{CT}$ and chest $\mathrm{X}$-ray (Figs. 1c, d and 2). The $\mathrm{S}^{6}$ a tumor was a pure ground-glass nodule with a diameter of $27 \mathrm{~mm}$; there was a distance from the basal segment. The $S^{9}$ tumor 

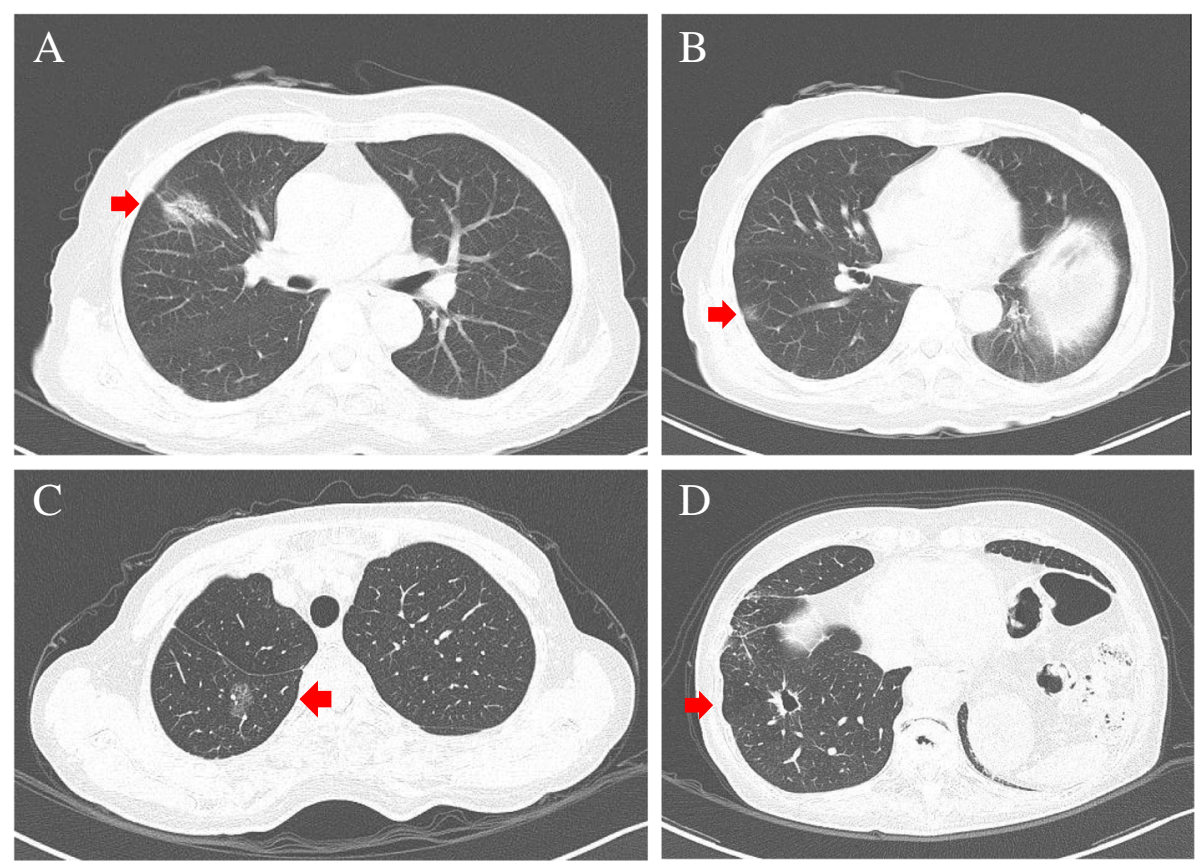

Fig. 1 Chest CT showing multiple lung tumors. a Right $\mathrm{S}^{2}$ tumor. The size was $28 \mathrm{~mm}$. b Right $\mathrm{S}^{6} \mathrm{~b}$ peripheral tumor. The size was $10 \mathrm{~mm}$. $\mathbf{c}$ Right $S^{6}$ a pure ground-glass nodule. The size was $27 \mathrm{~mm}$. d Right $S^{9}$ solid tumor near a bulla. The size was $21 \mathrm{~mm}$

diameter was $21 \mathrm{~mm}$, and it was solid and near a bulla in the CT image. The two tumors were suspected to be double primary carcinomas and were located in resectable sites. The patient had mild dyspnea on exertion. The modified Medical Research Council (mMRC) dyspnea score [1] was grade 2. In

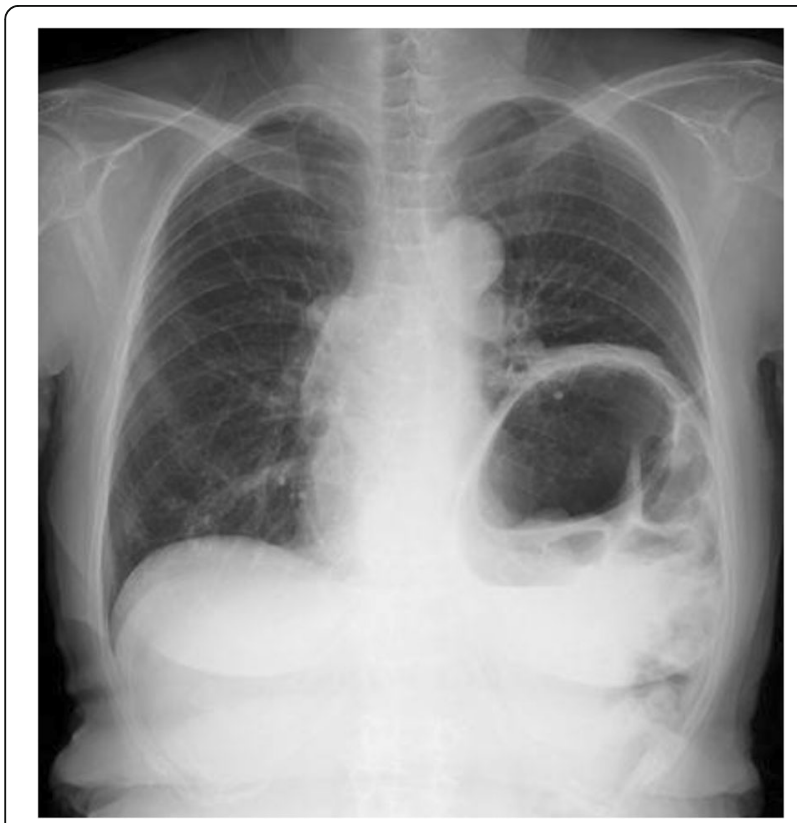

Fig. 2 Chest X-ray before diaphragm plication. The left diaphragm was elevated before plication addition, the result of her pulmonary function test (PFT) was poor; her forced vital capacity (FVC), \%FVC, forced expiratory volume in 1 second $\left(\mathrm{FEV}_{1}\right)$, $\mathrm{FEV}_{1} / \mathrm{FVC}$, and $\% \mathrm{FEV}_{1}$ were $1.54 \mathrm{~L}, 70.0 \%, 0.92 \mathrm{~L}$, $59.7 \%$, and $58.6 \%$, respectively (Table 1 ). We first concluded that her pulmonary function was too low to undergo pulmonary resection. There was a possibility that her poor pulmonary function was partly due to the left diaphragmatic eventration and that it could be improved with diaphragm plication.

We first performed VATS diaphragm plication with $\mathrm{CO}_{2}$ insufflation. During the operation, the patient was positioned in a full lateral decubitus position. Four air-locking trocars were placed; the $12-\mathrm{mm}$ trocars were inserted through the fifth intercostal space at the midaxillary line, the seventh intercostal space at the posterior axillary line, and the sixth intercostal space at the anterior axillary line. The $5-\mathrm{mm}$ trocars were placed at the eighth intercostal space at the midaxillary line. $\mathrm{CO}_{2}$ gas was insufflated at $8 \mathrm{mmHg}$ pressure through the trocar under thoracoscopic guidance. The diaphragm was sutured from the posterolateral portion to the anteromedial portion using 90cm-long, \#2-0 Ethibond ${ }^{\circ}$ (Ethicon, USA) threads with interrupted sutures (Fig. 3).

Two months after the procedure, she reported a very good improvement in her symptoms, and her PFT showed improvement; her FVC improved to $2.09 \mathrm{~L}$, \%FVC to $90.1 \%, \mathrm{FEV}_{1}$ to $1.31 \mathrm{~L}, \mathrm{FEV}_{1} / \mathrm{FVC} \%$ to $62.7 \%$, 
Table 1 Change in pulmonary function

\begin{tabular}{llll}
\hline & Preoperative & $\begin{array}{l}\text { After diaphragm } \\
\text { plication }\end{array}$ & $\begin{array}{l}\text { After pulmonary } \\
\text { resection }\end{array}$ \\
\hline FVC (L) & 1.54 & 2.09 & 1.49 \\
$\%$ FVC (\%) & 70.0 & 90.1 & 69 \\
$\mathrm{FEV}_{1}(\mathrm{~L})$ & 0.92 & 1.31 & 1.06 \\
$\mathrm{FEV}_{1} / \mathrm{FVC}(\%)$ & 59.7 & 62.7 & 71.1 \\
\%FEV $_{1}(\%)$ & 58.6 & 73.2 & 71.1 \\
\hline
\end{tabular}

$F V C$ forced vital capacity, $F E V_{1}$ forced expiratory volume in one second

and $\% \mathrm{FEV}_{1}$ to $73.2 \%$ (Table 1 ). A chest $\mathrm{X}$-ray revealed the expansion of the left lower lung and a flattened left hemidiaphragm (Fig. 4). The result of the arterial blood gas analysis was improved; the preoperative arterial blood oxygen partial pressure $\left(\mathrm{PaO}_{2}\right)$ was $79.3 \mathrm{mmHg}$ and the postoperative $\mathrm{PaO}_{2}$ was $93.7 \mathrm{mmHg}$ (Table 2).

Encouraged by the results, we decided to proceed with lung cancer surgery on the contralateral side and performed a right $S^{6}$ wedge resection and right $S^{9}$ segmentectomy for the double lung tumors. The tumors were diagnosed as double primary carcinomas. The surgical margins of the two tumors were both negative for malignancy. Three months following the last operation, her PFT values were acceptable (Table 1). She was discharged and her respiratory symptoms have not deteriorated to date. The mMRC dyspnea score was grade 1.

\section{Discussion}

This was a case of multiple metachronous carcinomas of the right lung complicated by left diaphragmatic eventration. The decision of which treatment methods to employ in this case was difficult because there were no similar case reports based on our literature search.

The treatment strategies for multiple lung tumors depend on the physical status of the patient. Surgical resections are considered if patients are expected to have sufficient physical functions following resection. An aggressive surgical approach has been reported as a safe and justified method for most patients with multiple primary lung cancers [2]. The selection of surgical methods is important for resection. In our case, the CT image showed that the right $\mathrm{S}^{9}$ tumor was $21 \mathrm{~mm}$, solid, and near a bulla. We chose a segmentectomy for the right $S^{9}$ tumor because these characteristics suggested the possibility of high-grade malignancy.

When evaluating the preoperative status of patients, preoperative physiologic assessments are important [3]. In cases where both $\%$ predicted postoperative (ppo)-FEV $\mathrm{F}_{1}$ and \%ppo-diffusing capacity of the lungs for carbon monoxide (DLCO) values are less than $60 \%$, the patient is considered to have a high risk for complications following anatomic lung resection [4]. In our case, the initial $\% \mathrm{FEV}_{1}$ was $58.6 \%$, and we thought the patient had a high risk for pulmonary resection. We nearly abandoned surgical treatment because of her poor pulmonary function; however, we suspected that her poor pulmonary function was caused by the left diaphragmatic eventration and considered performing diaphragm plication to possibly improve her respiratory function. Her pulmonary function improved after diaphragm plication; therefore, this strategy was successful and effective.

Diaphragmatic elevation is a condition caused by phrenic nerve injury or congenital diaphragm eventration. The indications for diaphragm plication are usually dyspnea with low pulmonary function. Diaphragm plication is a well-established surgical procedure that substantially improves dyspnea and objective measures of pulmonary function in patients who are symptomatic from diaphragm paralysis or eventration [5-7]. Diaphragm plication is a safe and effective procedure for adult patients with dyspnea due to unilateral diaphragmatic paralysis [5]. In our case, the patient had mild difficulty breathing. Furthermore, the improvement of her pulmonary function was necessary to safely perform the contralateral lung resection. In symptomatic patients with unilateral diaphragm paralysis, global inspiratory strength is reduced due not

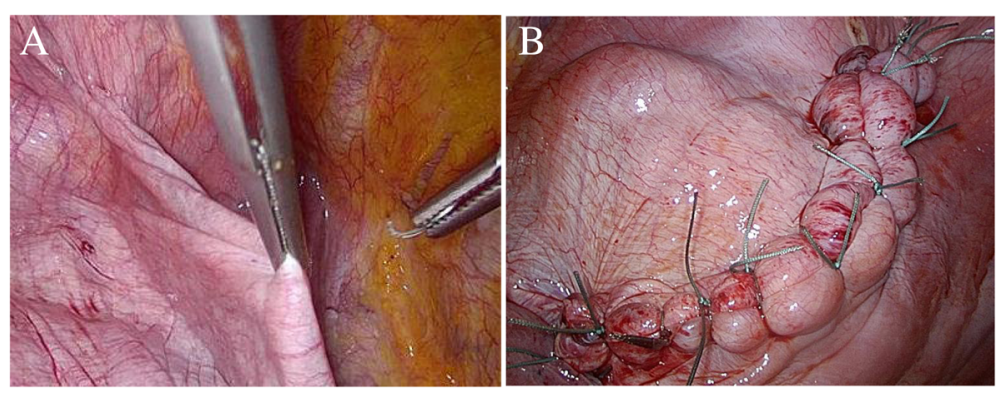

Fig. 3 Intraoperative photographs. a The diaphragm was nearly flat using $\mathrm{CO}_{2}$ insufflation. b After completion of diaphragmatic sutures 


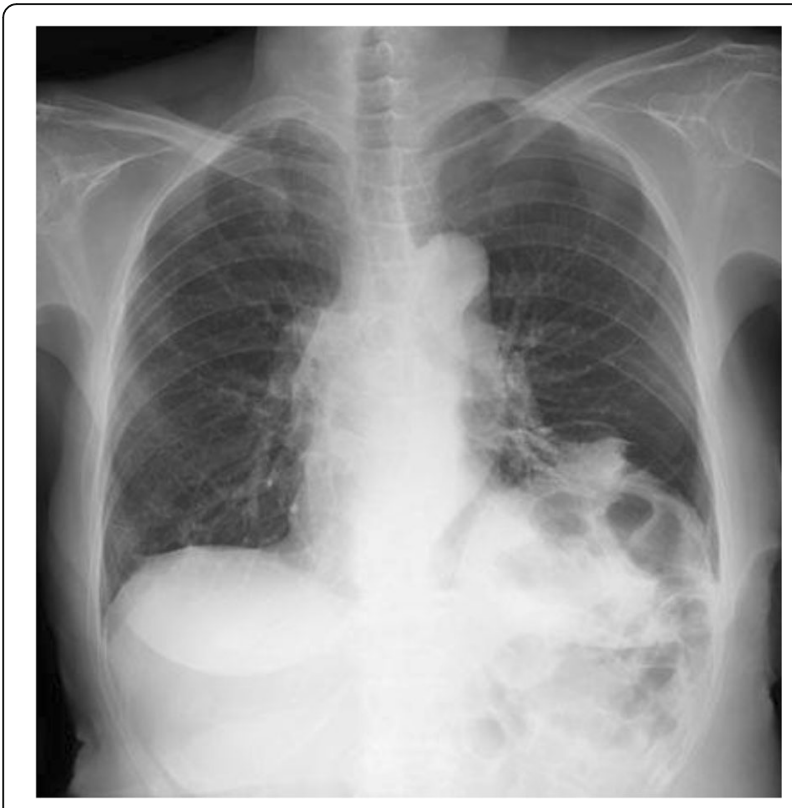

Fig. 4 Chest X-ray after diaphragm plication. The improvement in the left lung expansion after plication

only to weakness in the paralyzed hemidiaphragm but also to impairment in the pressure generated by the non-paralyzed hemidiaphragm [8]. In our case, unilateral diaphragm plication might have influenced the contralateral diaphragm movement.

In our case, we needed a minimally invasive surgical technique to treat the diaphragmatic eventration and perform the operation for the contralateral lung carcinomas. We selected VATS with $\mathrm{CO}_{2}$ insufflation due to the reduced risk of morbidity compared to that associated with open thoracotomy. The fact that thoracotomy itself is known to reduce diaphragm function transiently $[9,10]$ and that this deficit recovers more quickly after VATS than after thoracotomy [11] is important when selecting a procedure. Using $\mathrm{CO}_{2}$ insufflation for thoracoscopic plication was effective, and VATS with $\mathrm{CO}_{2}$ insufflation is becoming common. $\mathrm{CO}_{2}$ gas insufflation provided excellent working space and made the stitching easy until the diaphragm was nearly flat [12]. The simplicity of this operation may be safe and is

Table 2 Change in arterial blood gas (room air)

\begin{tabular}{lll}
\hline & Preoperative & After diaphragm plication \\
\hline $\mathrm{pH}$ & 7.430 & 7.419 \\
$\mathrm{PaO}_{2}(\mathrm{mmHg})$ & 79.3 & 93.7 \\
$\mathrm{PaCO}_{2}(\mathrm{mmHg})$ & 45.4 & 42.4 \\
$\mathrm{BE}(\mathrm{mmol} / \mathrm{L})$ & 4.5 & 2.1 \\
$\mathrm{SaO}_{2}(\%)$ & 96.5 & 97.6
\end{tabular}

$\mathrm{PaO}_{2}$ arterial blood oxygen partial pressure, $\mathrm{PaCO}_{2}$ arterial blood carbon dioxide partial pressure, $\mathrm{BE}$ base excess, $\mathrm{SaO}_{2}$ arterial oxygen saturation associated with a low risk of morbidity for patients. There is a possibility that the intrathoracic pressure can become too high, but low-pressure insufflation up to 10 mmHg produced no deleterious effects on the patient's hemodynamic status [13].

\section{Conclusions}

We report a case of low pulmonary function, multiple carcinomas of the right lung and left diaphragmatic eventration. We performed VATS plication for left diaphragmatic eventration and achieved improvement in the patient's respiratory function. Then, we performed right pulmonary resection for the lung carcinomas. VATS plication may not only lead to an improvement in pulmonary function but also expand the choices for lung disease treatment.

\section{Acknowledgements}

Not applicable.

\section{Authors' contributions}

YM, SY, and TI performed the operations. YM, SY, TY, KT, and TI managed the postoperative intensive care. All authors conceived the study and participated in its design and coordination. YM drafted the manuscript. All authors read and approved the final manuscript.

Funding

Not applicable.

Availability of data and materials

Not applicable.

Ethics approval and consent to participate Not applicable.

\section{Consent for publication}

Informed consent was obtained from the patient and the patient's family for the publication of this case report.

\section{Competing interests}

The authors declare that they have no competing interests.

\section{Author details}

${ }^{1}$ Department of Thoracic Surgery, Chiba Cancer Center, 666-2 Nitona-cho, Chuo-ku, Chiba 260-8717, Japan. ${ }^{2}$ Department of Thoracic Surgery, International University of Health and Welfare School of Medicine, Narita, Japan. ${ }^{3}$ Department of General Thoracic Surgery, Graduate School of Medicine, Chiba University, Chiba, Japan.

Received: 29 March 2019 Accepted: 21 May 2019

Published online: 30 May 2019

\section{References}

1. Launois C, Barbe C, Bertin E, Nardi J, Perotin JM, Dury S, Lebargy F, Deslee G. The modified Medical Research Council scale for the assessment of dyspnea in daily living in obesity: a pilot study. BMC Pulm Med. 2012;12(1): 61. https://doi.org/10.1186/1471-2466-12-61.

2. Adebonojo SA, Moritz DM, Danby CA. The results of modern surgical therapy for multiple primary lung cancers. Chest. 1997;112(3):693-701.

3. Nakahara K, Monden Y, Ohno K, Miyoshi S, Maeda H, Kawashima Y. A method for predicting postoperative lung function and its relation to postoperative complications in patients with lung cancer. Ann Thorac Surg. 1985;39(3):260-5.

4. Sawabata N, Nagayasu T, Kadota Y, Goto T, Horio H, Mori T, Yamashita S, Iwasaki A. Risk assessment of lung resection for lung cancer according to pulmonary function: republication of systematic review and proposals by 
guideline committee of the Japanese association for chest surgery 2014 Gen Thorac Cardiovasc Surg. 2015;63(1):14-21.

5. Graham DR, Kaplan D, Evans CC, Hind CR, Donnelly RJ. Diaphragmatic plication for unilateral diaphragmatic paralysis: a 10-year experience. Ann Thorac Surg. 1990;49:248-52.

6. Versteegh MI, Braun J, Voigt PG, Bosman DB, Stolk J, Rabe KF, et al. Diaphragm plication in adult patients with diaphragm paralysis leads to long-term improvement of pulmonary function and level of dyspnea. Eur . Cardiothorac Surg. 2007;32:449-56.

7. Celik S, Celik M, Aydemir B, Tunckaya C, Okay T, Dogusoy I. Long-term results of diaphragmatic plication in adults with unilateral diaphragm paralysis. J Cardiothorac Surg. 2010;5:111.

8. Caleffi-Pereira M, Pletsch-Assunção R, Cardenas LZ, Santana PV, Ferreira JG, lamonti VC, Caruso P, Fernandez A, de Carvalho CRR, Albuquerque ALP. Unilateral diaphragm paralysis: a dysfunction restricted not just to one hemidiaphragm. BMC Pulm Med. 2018;18(1):126

9. Melendez JA, Alagesan R, Reinsel R, Weissman C, Burt M. Postthoracotomy respiratory muscle mechanics during incentive spirometry using respiratory inductance plethysmography. Chest. 1992;101:432-6.

10. Maeda H, Nakahara K, Ohno K, Kido T, Ikeda M, Kawashima Y. Diaphragm function after pulmonary resection: relationship to postoperative respiratory failure. Am Rev Respir Dis. 1988:137:678-81.

11. Nomori H, Ohtsuka T, Horio H, Naruke T, Suemasu K. Difference in the impairment of vital capacity and 6-minute walking after a lobectomy performed by thoracoscopic surgery, an anterior limited thoracotomy, an anteroaxillary thoracotomy, and a posterolateral thoracotomy. Surg Today. 2003;33:7-12.

12. Homma T, Yamamoto Y, Doki Y, Senda K, Touge M, Ojima T, Shimada Y, Yoshimura N. Complete thoracoscopic diaphragm plication using carbon dioxide insufflation: report of a case. Surg Today. 2015;45(7):915-8.

13. Ohtsuka T, Imanaka K, Endoh M, Kohno T, Nakajima J, Kotsuka Y, Takamoto S. Hemodynamic effects of carbon dioxide insufflation under single-lung ventilation during thoracoscopy. Ann Thorac Surg. 1999;68:29-33.

\section{Publisher's Note}

Springer Nature remains neutral with regard to jurisdictional claims in published maps and institutional affiliations.

\section{Submit your manuscript to a SpringerOpen ${ }^{\circ}$ journal and benefit from:}

- Convenient online submission

- Rigorous peer review

- Open access: articles freely available online

- High visibility within the field

- Retaining the copyright to your article 